\title{
月一十年二十三治 明
}

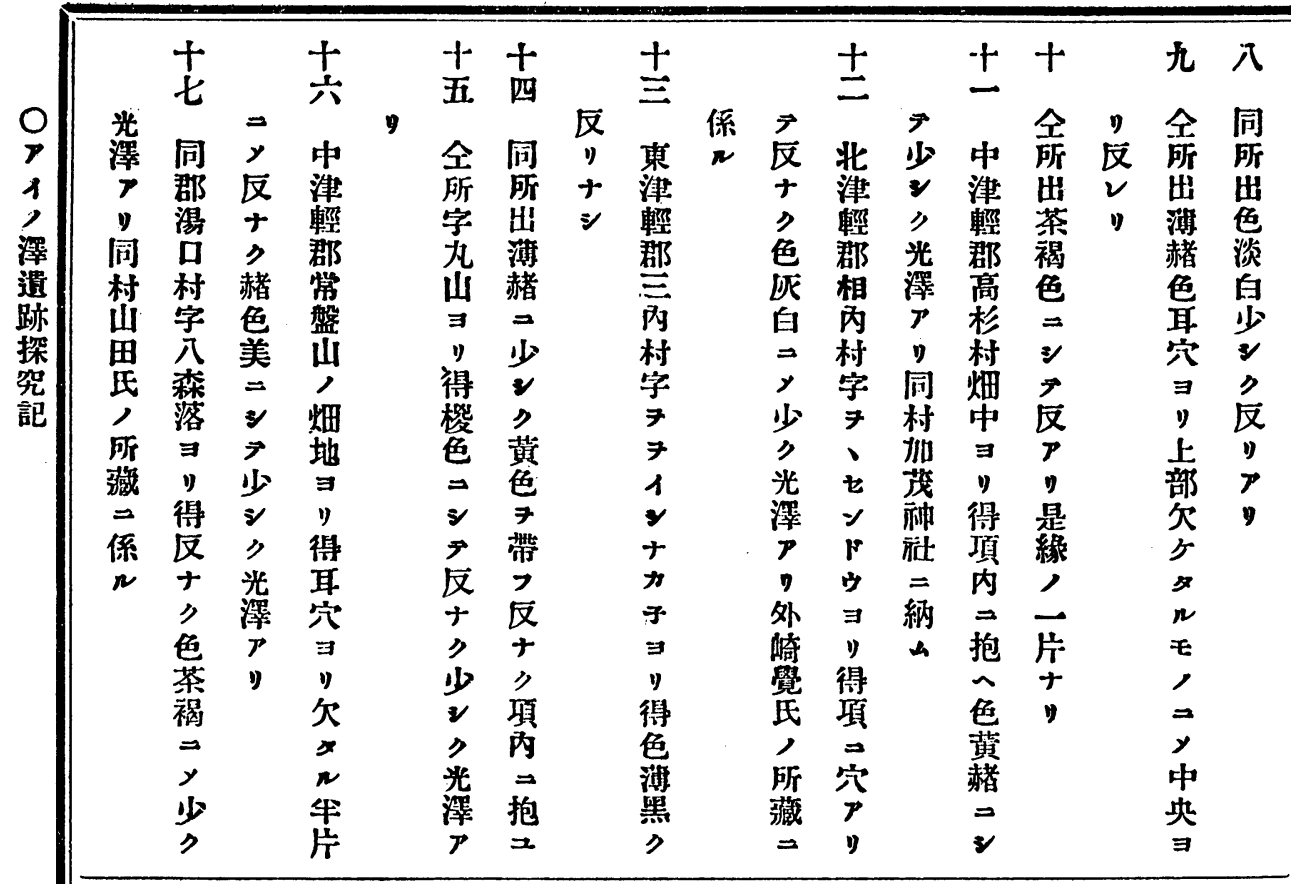

至 餘長 尺

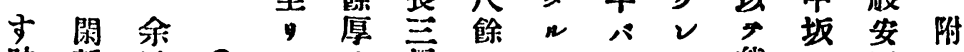

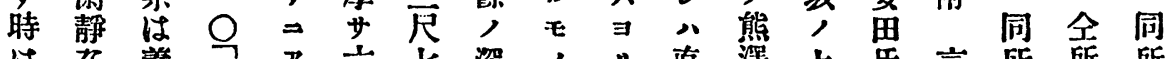

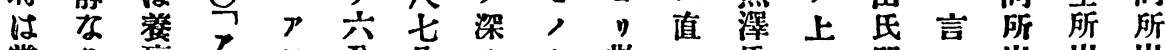

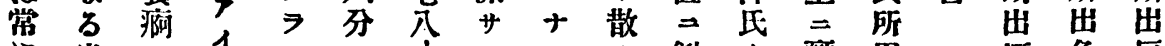

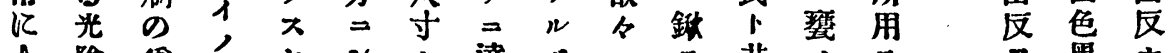

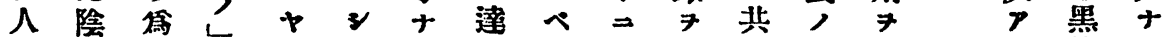

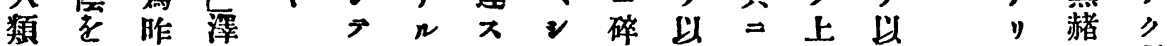

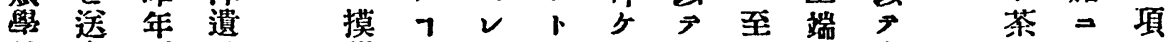

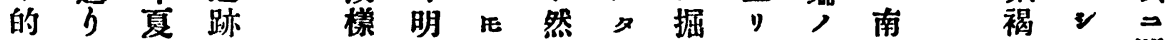

の片 の 探

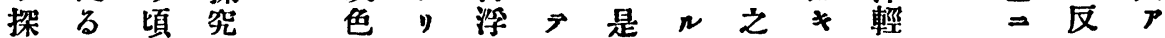

究加よ記右其紋其 $\nu=F$ 者郡

を其 5 甲 穴, 器雨遗見見黑

四

篇間 圖庄下, 露憾n, 石

共年 $=7$ 部底, $+\Rightarrow v=$

同見ナ埋雼几果早赴

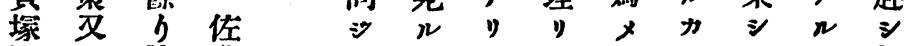

㹂は陸藤㗼 $\Rightarrow 1$

穴旅啭

土行國重惜德入地脆柔人, 人

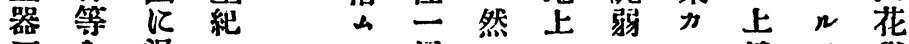

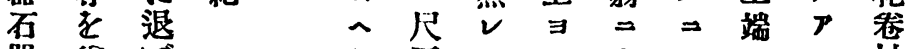

\& 0 V

$\boldsymbol{P}$ 莱

少y䄓

外任

”崎 ナ

光覺 》

器秈 て

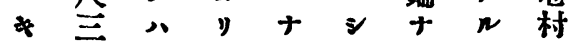

㳯 民

7 武

$=$

係 


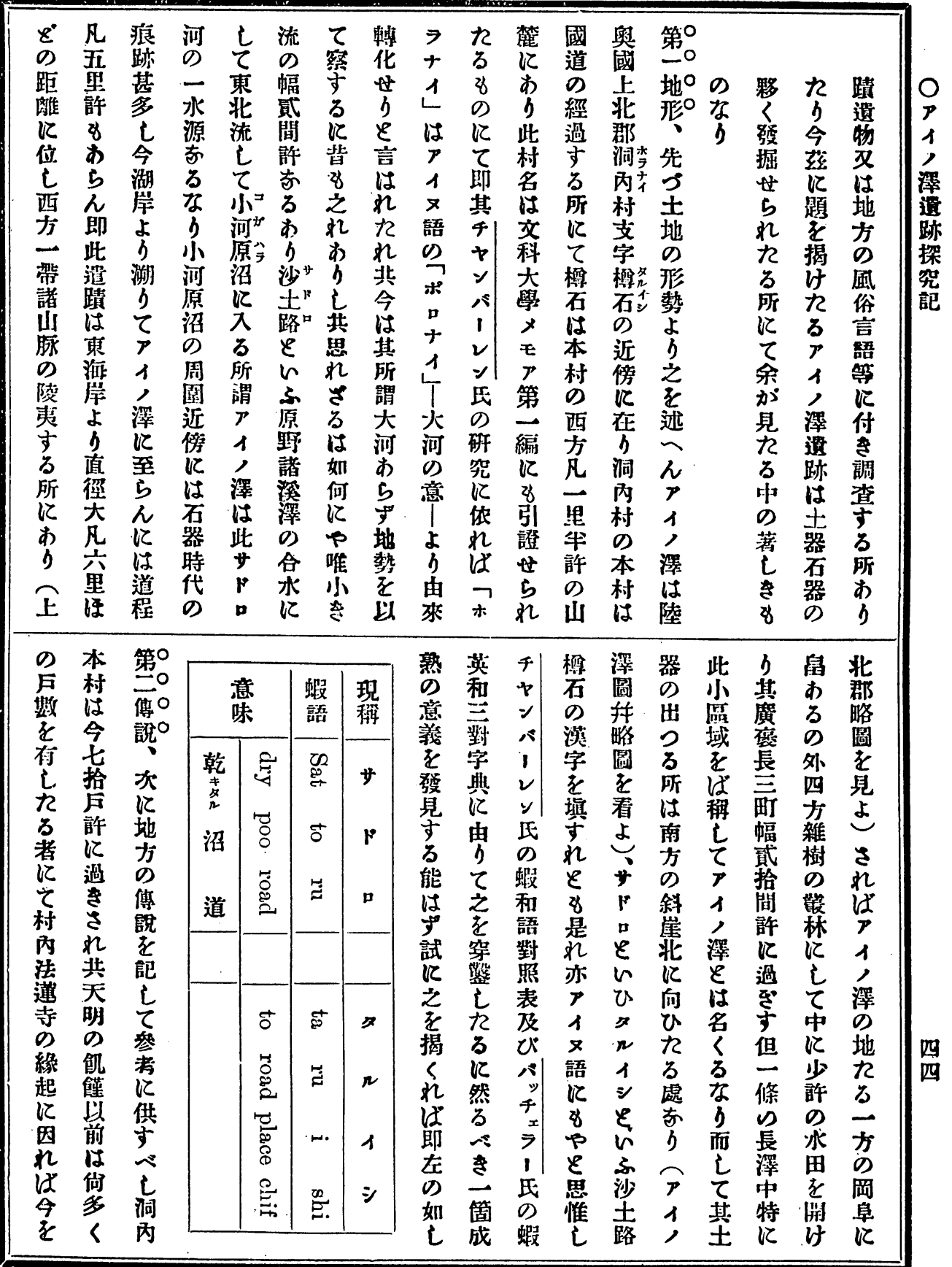




\section{月一十年二十二尚 明}

;

1

政

in

慗

婉

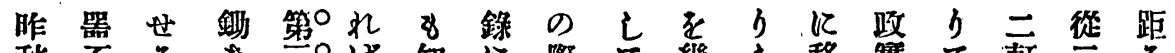

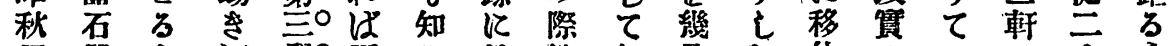

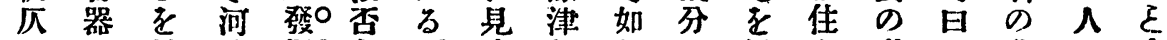

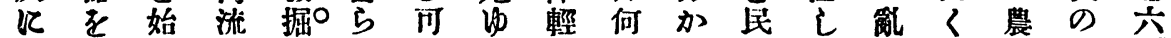

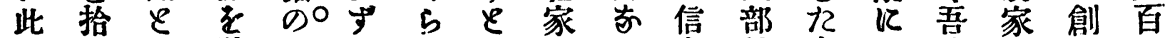

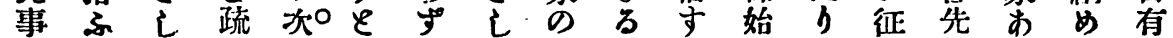

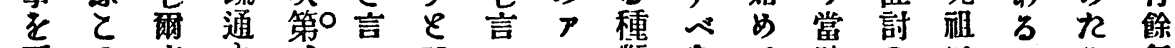

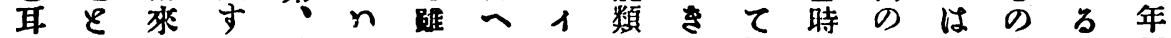
にあ大る

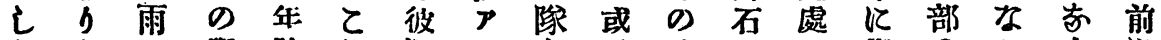

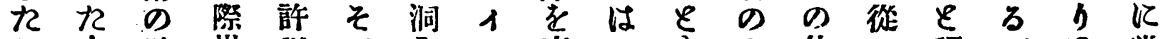

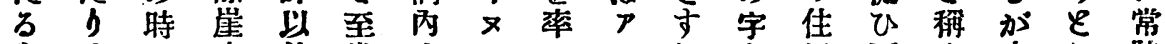

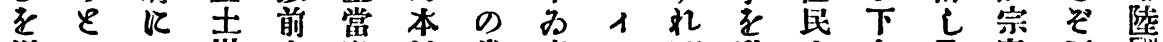

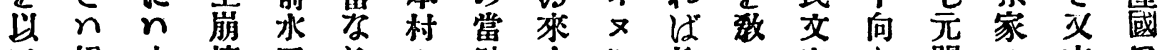

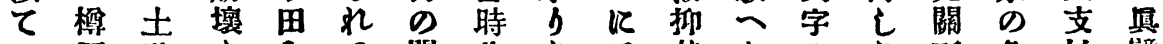

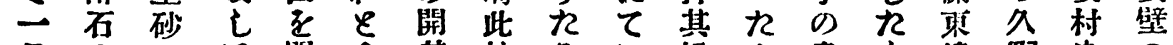

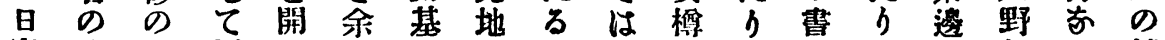

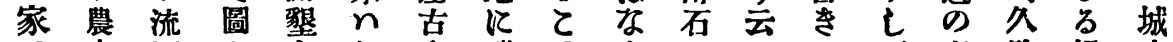

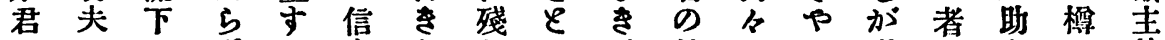

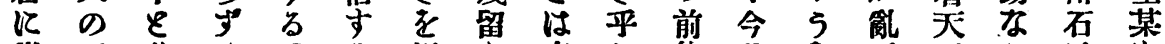

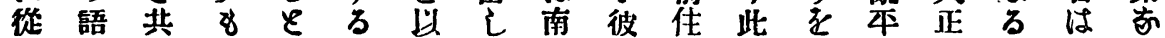

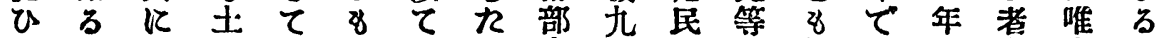

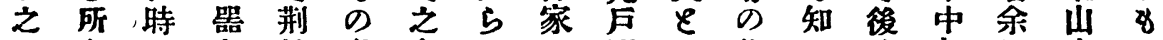
になくを赖なをんの强は傳ら此九に中の

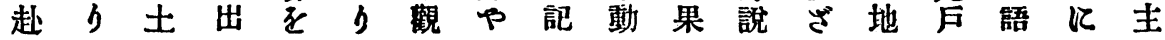

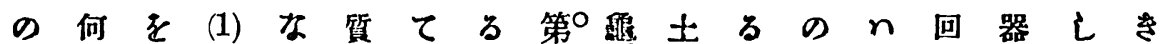

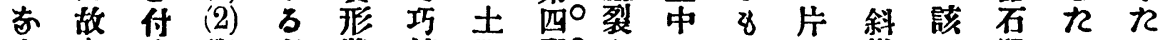

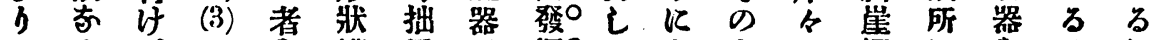

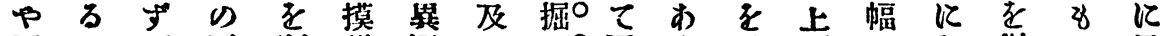

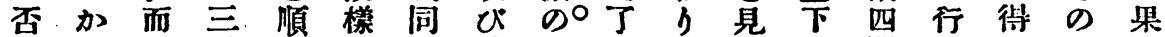

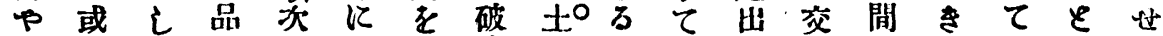

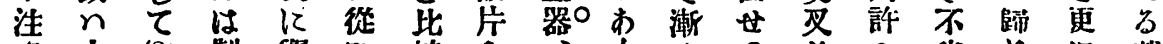
意之 (2) 製 譽 ひ 㜞を

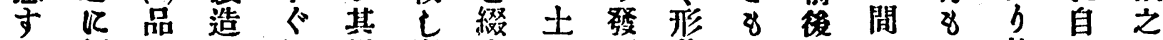

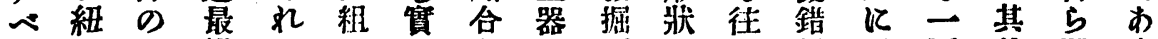

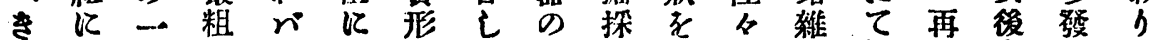

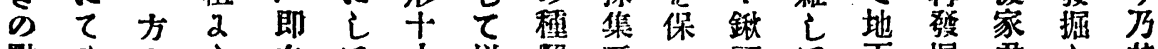

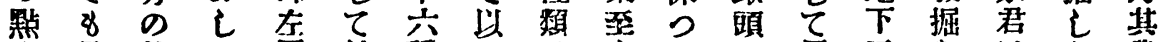

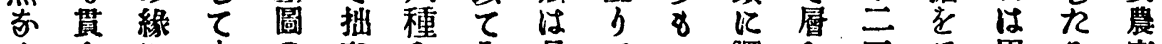

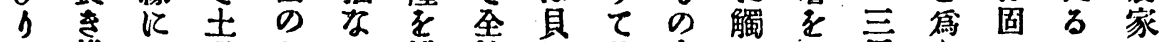

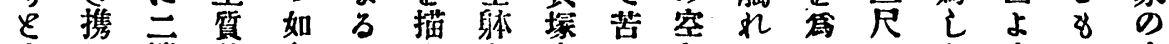

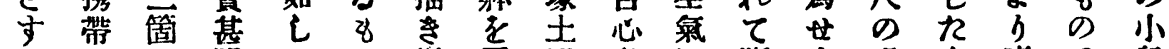

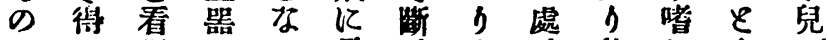
便小く机得 2 万巽碎中破其好合方

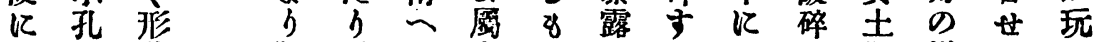

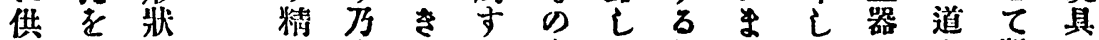

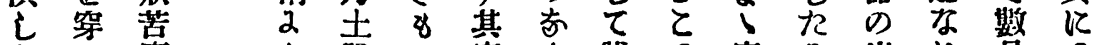

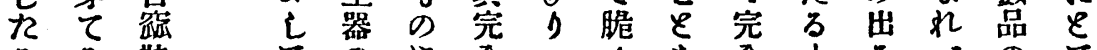

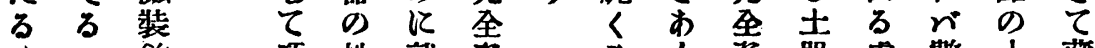

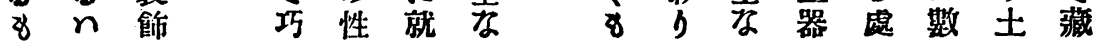




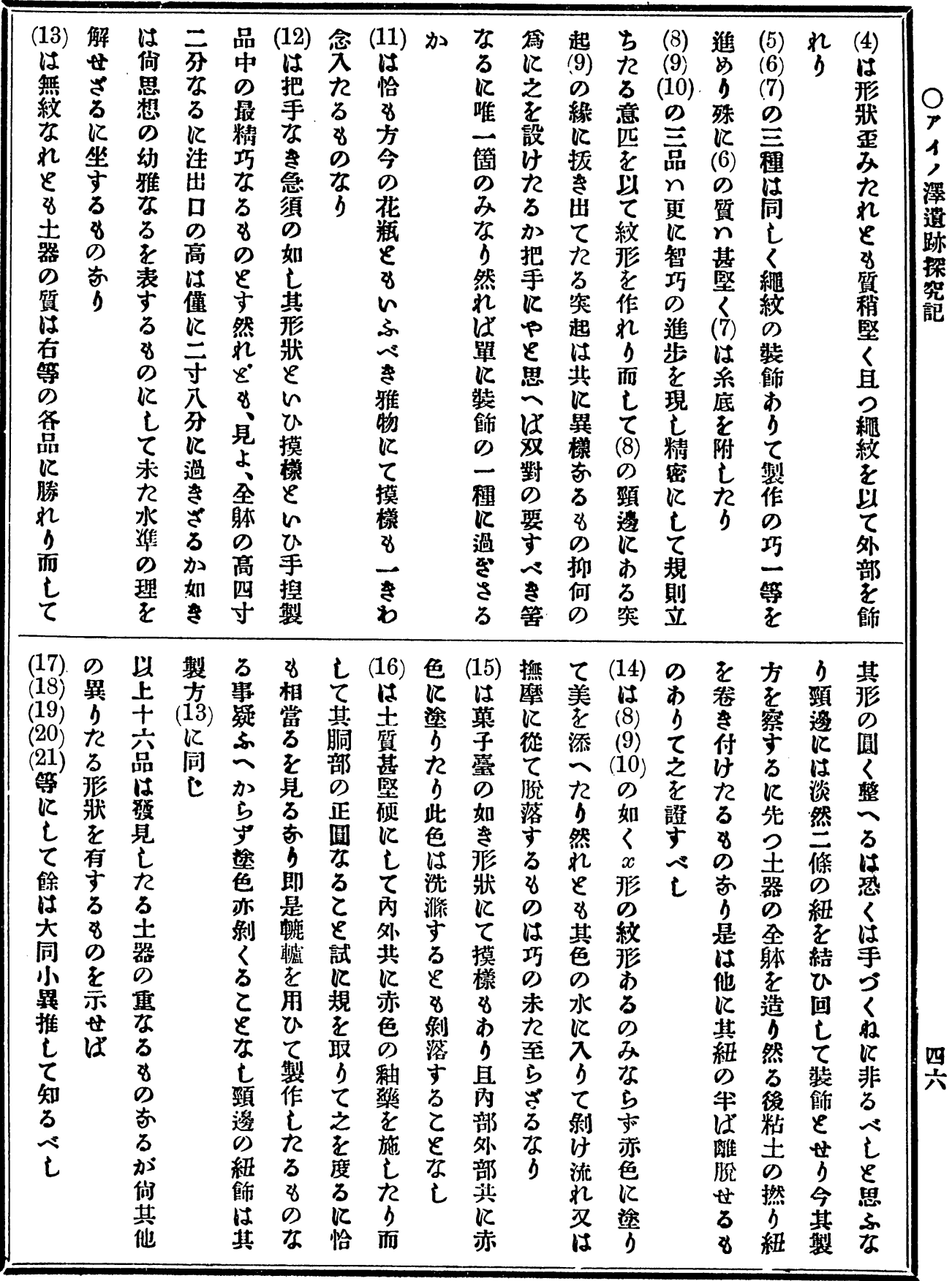




$$
\text { 月一十年二十二治明 }
$$
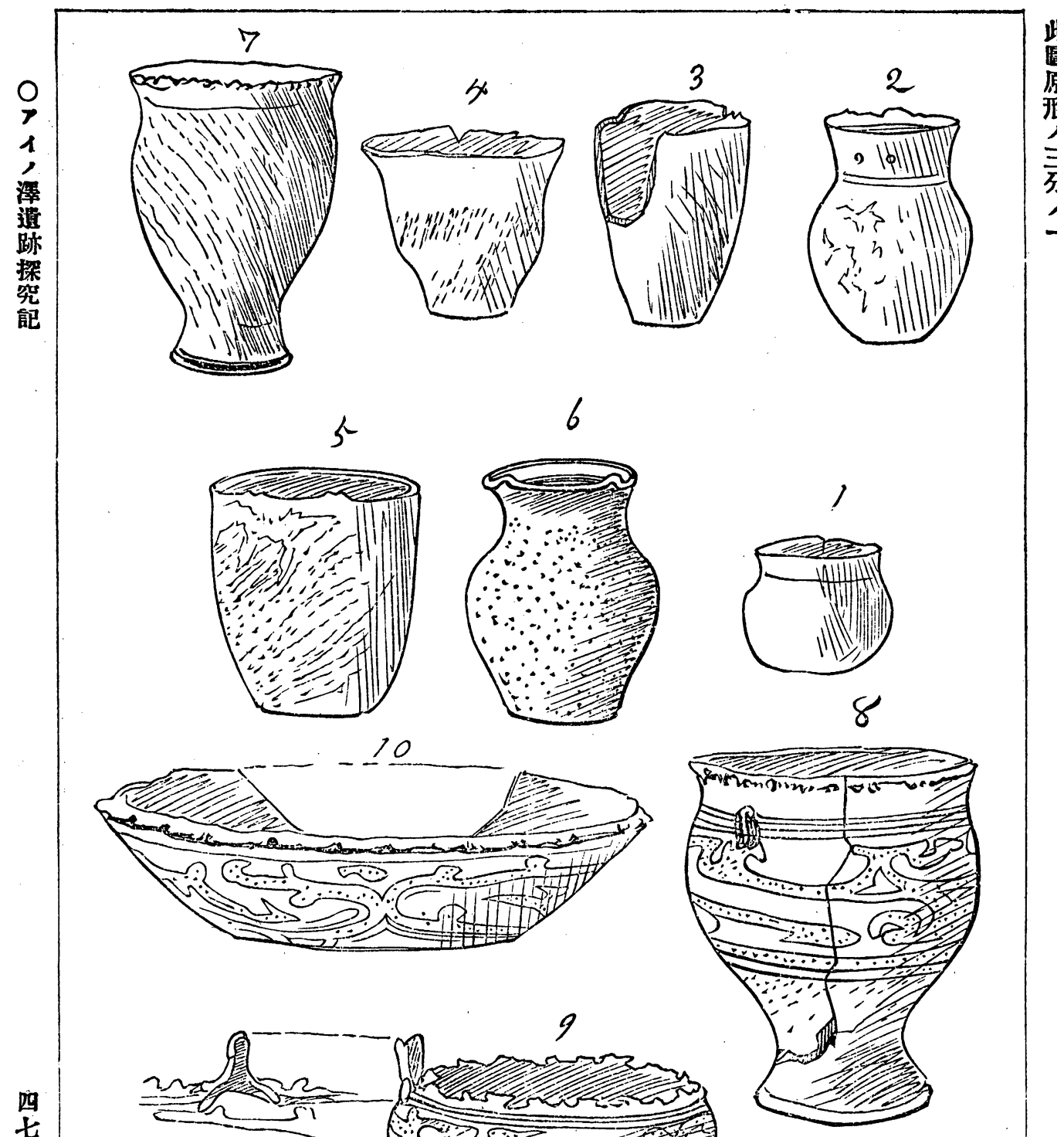
號五十四第誌雜會學類人京束






\section{月 一十年二十二流明}

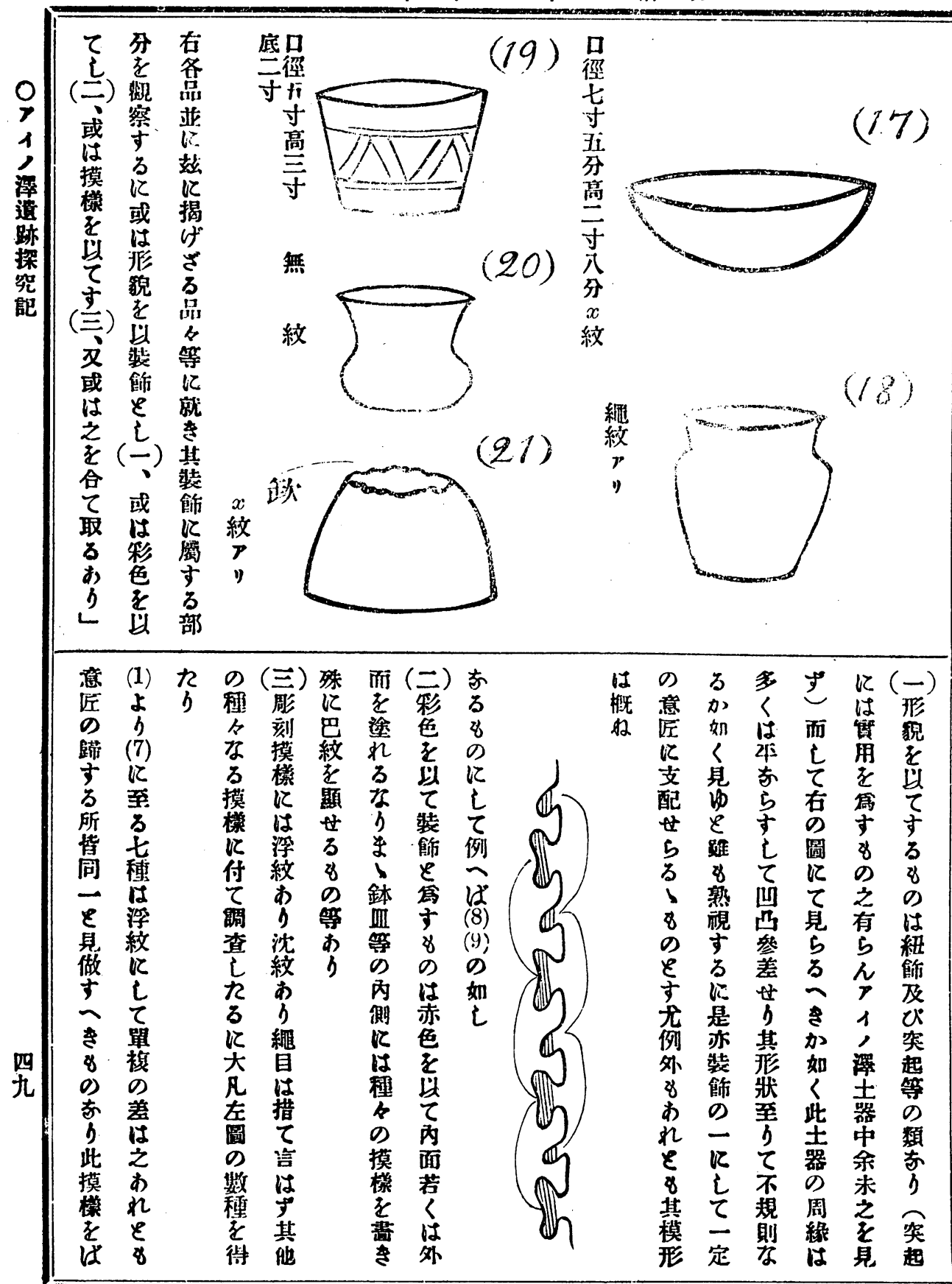




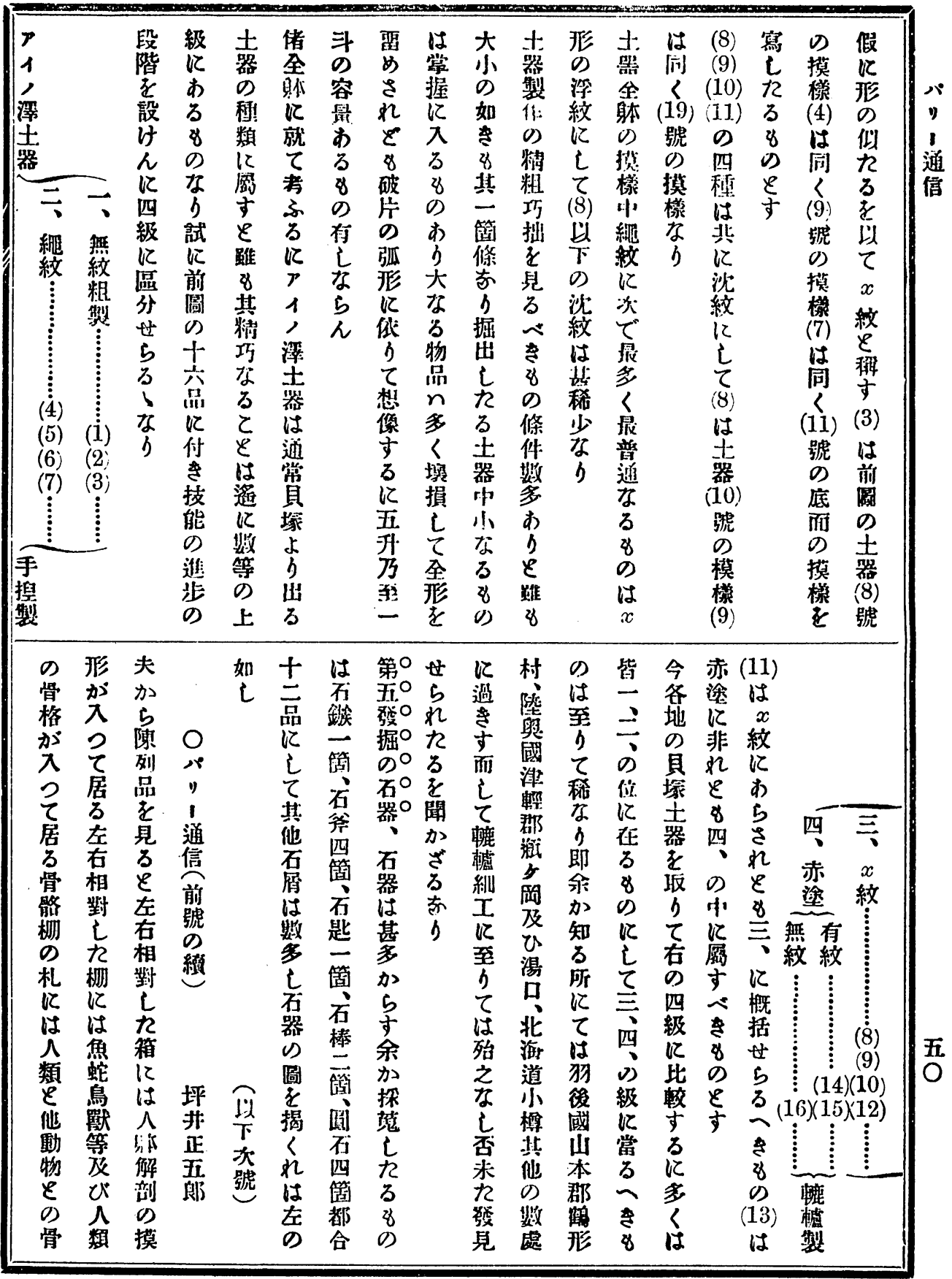

